\title{
La división provincial española: antecedentes, evolución y estado actual ${ }^{1}$
}

\author{
Marc Tarrés Vives \\ Profesor Agregado de Derecho Administrativo \\ Universidad de Barcelona
}

\begin{abstract}
Sumario: 1. Introducción.-2. Antecedentes y origen de la provincia. 2.1. La expresión provincia. 2.2. La necesidad de una división territorial racional en el tránsito del Antiguo régimen al Estado liberal. 2.3. La impronta del modelo francés en la división de 1833.-3. La posterior evolución del régimen provincial hasta el franquismo. - 4. La Constitución Española de 1978 y la garantía constitucional de la provincia. 5. Presente y futuro de la provincia en el siglo XXI ¿Una nueva división provincial? Bibliografía.
\end{abstract}

\section{INTRODUCCIÓN}

La provincia española se encamina, a escasamente dos décadas, hacia su bicentenario. Enraizada para unos y cuestionada por otros, lo cierto es que el ente provincial por excelencia, la Diputación provincial, aparece en el momento de escribir estas líneas con un futuro más prometedor que el que parecía augurarse hace sólo unos meses. La apenas sostenible situación financiera de nuestras Administraciones públicas, y singularmente las de carácter local, suscitó en estos últimos años un intenso debate que ha terminado por cristalizar en diferentes documentos e iniciativas legislativas que el tiempo se encargará de mostrar su cordura o desacierto. Entre los primeros debe citarse el informe elaborado por la Comisión para la Reforma de las Administraciones Públicas (CORA), allí se refiere el anteproyecto, ahora ya Proyecto de Ley de Racionalización y Sostenibilidad de la Administración Local, aprobado en sede de Consejo de Ministros el pasado 26 de julio de 2013. Pues bien, la CORA refiere que la nueva reforma local va a suponer ni más ni menos que el ahorro de al menos 7.129 millones de euros en el periodo 2013-2015, y tan encomiable objetivo se va a conseguir en gran medida gracias al reforzamiento del papel de las Diputaciones Provinciales y entes equivalentes. Finalidad encomiable que habrá que ver cómo se lleva a la práctica y qué efectos produce.

1. El presente texto, con alguna leve modificación posterior, fue presentado en el marco del seminario italo-español que bajo el título «La crisi economica ed i suoi riflessi sull'ordinamento costituzionale» se celebro en el 22 de marzo en la Scuola Superiore Sant'Anna de Pisa. 
El objeto de este trabajo no es, sin embargo, el de abordar las funciones que pueden llevar a cabo las Diputaciones provinciales en ese nuevo escenario, sino ofrecer una panorámica sobre los orígenes y evolución del hecho provincial en nuestro país con una apuesta por un nuevo mapa acorde con la realidad política, económica y social de la España del siglo XXI.

\section{ANTECEDENTES Y ORIGEN DE LA PROVINCIA}

\subsection{La impronta castellana}

Uno de los aspectos clave para comprender la división provincial española de 1833 es conocer que la misma se realiza, en buena medida, a partir de una realidad organizativa y política preexistente conformada en la Corona de Castilla. Siendo así que lo que a finales del siglo XVI se entiende por provincia en tierras castellanas es una entidad reducida en el espacio, aminorada en lo político, y ligada siempre a una realidad urbana. Es así que la provincia castellana se articula a partir de las ciudades con Voto en Cortes teniendo un exclusivo carácter fiscal y careciendo de cualquier función administrativa o judicial.

Una acepción que, como se observará más adelante, no es en absoluto compartida en todos los territorios hispánicos, cuando menos en el Principado de Cataluña. Cuatro son los elementos que permiten sostener esta afirmación sobre la impronta castellana:

1. Todas las ciudades que en Castilla eran capital de provincia en vísperas de la Constitución de Cádiz siguieron siéndolo en la división vigente desde 1833

2. En parte como consecuencia de esto, la dimensión media de las provincias en la meseta acabó siendo el patrón de referencia que se trasladó a otros territorios (Cataluña, Valencia, Galicia, cuyas provincias tomarán al igual que las castellanas el nombre de sus capitales, a diferencia de las provincias vascas y de Navarra). Por tanto, en lugar de fusionar provincias se optó por fragmentar las que eran entonces más extensas.

3. La división de 1833 ofrece una notable singularidad que es la excepción vasca, anómala en relación no sólo en lo geográfico (son las provincias de menor tamaño), sino también en lo fiscal y político. Excepción que se comprende únicamente al ser, al fin y al cabo, parte constitutiva de una realidad que no es otra que la de la Corona de Castilla, de la que, sin duda, fueron las Provincias por excelencia.

Todo ello explica que en la España liberal la provincia se conforme como un ente meramente administrativo, subalterno del poder central y sin 
poder político alguno, en la línea que había sido la provincia en la Corona de Castilla.

\subsection{La necesidad de una división territorial racional en el tránsito del Antiguo régimen al Estado liberal}

El segundo elemento indispensable para comprender la división provincial de 1833 es el de su contextualización, es decir el momento en que se produce. Durante el convulso primer tercio del siglo XIX España vive la invasión napoleónica, ve la instauración de una nueva monarquía, sufre una Guerra de Independencia durante la cual se aprueba la Constitución de 1812. Primer texto constitucional en sentido propio que recordemos hace residir la soberanía en la Nación y no ya en el Rey. Tras la guerra se asiste a la vuelta de los Borbones seguida de una revolución liberal que intenta marchar por la senda constitucional pero termina truncada con la entrada de los cien mil hijos de San Luis que dará paso, entre 1823 y 1833, a la llamada década ominosa, tras la cual vendrán dos años de una transición ambigua durante los cuales se implanta de manera definitiva la división provincial.

Pues bien, el tema de la división territorial irá estrechamente ligado a todos y cada uno de estos diferentes avatares hasta que en el momento más insospechado, tras la muerte de Fernando VII y teniendo la regente al mismo jefe de gabinete que el difunto rey -Cea Bermúdez-, su recién nombrado Ministro de Fomento, Javier de Burgos, impulsará un conjunto de decretos que debían dar «una nueva forma a la administración del país». Un personaje singular, Javier de Burgos, tanto o más que la época que le tocó vivir. Subprefecto en la España josefina (de Almería dependiente de Granada), será un hombre especialmente útil al rey deseado para garantizar la compra de deuda española en los mercados financieros internacionales de la época mediante actuaciones a las que no eran ajenas la desinformación y el soborno. Con todo se trata de una figura destacada que sin estar imbuido del espíritu de la Revolución sabrá aplicar las técnicas administrativas napoleónicas que permiten la organización del Estado liberal y sientan ya los fundamentos sobre los que surgiría el Derecho Administrativo. Como se ha escrito fue «nuestro primer ministro tecnócrata» y si bien su etapa a cargo del Ministerio de Fomento fue breve resultó altamente fecunda destacando de ella la división territorial en provincias a través del conocido Real decreto de 30 de noviembre de 1833. En él que quedan dibujadas 49 provincias ya que en el caso de Canarias se trataba entonces de una única provincia con capital en Santa Cruz de Tenerife. A este decreto debe añadirse el anterior de 23 de octubre de 1833, por el que se manda establecer Subdelegados de Fomento (agentes especiales de prosperidad dotados con fondos de policía) en «las provincias ya existentes y en las que se formen en la nueva división territorial», y, luego, del mismo 30 de noviembre, el decreto que contiene la detallada Instrucción dirigida a los Subdelegados. 
Sin embargo, sería erróneo decir que la división hecha en 1833 - y que perdura hasta día de hoy- aparece ex novo. Por el contrario es el resultado de antecedentes fácticos y normativos muy precisos así como de múltiples estudios y propuestas llevadas a cabo durante las dos décadas anteriores, e incluso antes con la propuesta hecha por Floridablanca.

No procediendo un mayor abundamiento, señalaremos que durante la invasión napoleónica el gobierno de José Bonaparte dictó un decreto de 17 de abril de 1810 por el que se dividió España en 38 prefecturas y 74 subprefecturas. Por su parte, la Constitución de Cádiz reconoce, sin definirla, una división territorial en provincias al prever Diputaciones provinciales dependientes del Jefe político, figura inspirada en su equivalente francés del Prefecto. Pero en cualquier caso el artículo 11 de este bicentenario texto remite a que sea una ley constitucional la que haga la división más conveniente al territorio español, una vez que las circunstancias políticas de la Nación lo permitan. No hay que olvidar que parte de ese territorio, caso de Cataluña, había sido agregado por Napoleón al Imperio francés.

Esas circunstancias parecerán darse durante el trienio liberal cuando se aprobó la que fue única división provincial aprobada en Cortes mediante el Decreto de 27 de enero de 1822 y acorde con lo previsto en el artículo 11 de la reinstaurada Constitución de 1812. Sin embargo, la división de 1822 va a tener un carácter marcadamente ahistórico (enumeración alfabética de las provincias; cancelación de límites tradicionales de los antiguos reinos; supresión de enclaves provinciales) que lo distingue de la posterior división de 1833 en la que se mantienen anteriores denominaciones o se crean nuevas, caso de Andalucía.

Por desgracia, este decreto, junto al de 3 de febrero de 1823 por el que se aprobaba la Instrucción para el gobierno económico-político de las provincias, iban a perder su vigencia con la reinstauración del rey absoluto. Pese a todo, durante los últimos estertores absolutistas se siguió trabajando en la división territorial, singularmente por el ingeniero de Caminos y Canales Agustín de Larramendi, persona clave a partir de 1820 en los sucesivos episodios de elaboración del mapa provincial. Si durante el trienio liberal colaboraría con el cartógrafo de la Marina Felipe Bauzá, posteriormente lo haría con el alto funcionario de Justicia José Lamas Pardo, que a la postre sería ministro universal del pretendiente Carlos María Isidro. Y finalmente, en 1833, de la mano de Javier de Burgos, se convertiría en Director general de Caminos

En síntesis puede afirmarse que la división provincial fue una obra colectiva, de paternidad difusa y múltiple y claramente hermanada con los acontecimientos del primer tercio del siglo XIX. Y si bien Javier de Burgos pudo haberse «apropiado» del trabajo ya hecho, no es tampoco menos cierto que había ido siguiendo los trabajos realizados durante el trienio liberal, tal como atestiguan sus artículos publicados en el periódico El Imparcial, en donde propugnaba 40 provincias, divididas en cuatro subdelegaciones y cada 
una de ellas dividida en cuatro partidos judiciales, porque no nos corresponde tratarlo aquí pero hay que señalar que la nueva división territorial fue de la mano de la no menos necesaria nueva planta judicial exigida por la desaparición de las jurisdicciones señoriales. De igual modo Javier de Burgos escribiría en una exposición dirigida al Rey en 1827 que «hay una multitud de instituciones aplicables tanto a los gobiernos absolutos como a los representativos, tanto a los legítimos como a los usurpadores (...)», siendo la división provincial una de esas instituciones. De Burgos no era, sin duda, un progresista pero sí un ilustrado, de los últimos que quedaban en España, completamente imbuido de los ideales del siglo de las luces.

\subsection{La impronta del modelo francés en la división de $\mathbf{1 8 3 3}$}

Llegados a este punto no es innecesario referir el incuestionable influjo que el modelo racionalista francés tiene sobre los ilustrados españoles en el momento de concebir la división territorial española. Un modelo que, en cambio, para otros, como el historiador catalán Antoni de Capmany, resulta inconcebible atendiendo a que es el apego al propio territorio lo que durante la Guerra de la Independencia se estaba demostrando fundamental para el triunfo de la resistencia.

Es comprensible el terror que en algunos podía despertar el modelo francés que de un plumazo había eliminado las antiguas divisiones y particularidades territoriales del Antiguo Régimen y en su lugar había impuesto la nueva división departamental. Una división por cierto inspirada por un provenzal (el célebre abate Sieyès) y un normando (Thouret, presidente de la Asamblea Constituyente) quienes, siguiendo al pie de la letra las utopías ilustradas elaboraron una división regular y matemática de Francia adoptando como base el número 9, cuadriculando así el territorio en 81 departamentos, de un modo igual a como se pretendía en los nacidos Estados Unidos. Sin embargo, Francia no era, a diferencia del otro lado del Atlántico, un territorio nuevo y virgen aún por explorar y colonizar. Ello obligó a tomar en cuenta la realidad preexistente y en consecuencia, al igual que en España, aflorarían rivalidades urbanas por entender lo que estaba en juego. El resultado fue una división, en 1790, de 83 departamentos que ascendería después, por la incorporación de nuevos territorios, a 90. El mapa final, aunque trazado de manera homogénea y regular no llegaría a la rigidez geométrica de un tablero de ajedrez, y no dejaba de evocar antiguos territorios si bien con el nombre cambiado por apelativos orográficos, hidrográficos, puntos cardinales e incluso evocaciones vitícolas como la de Côte d'Or.

Ahora bien, hay que reconocer la existencia de diferencias entre la división provincial española y la departamental:

1. La diferente extensión

2. El no uso de denominaciones geográficas, sino históricas, así como el respeto a límites históricos 
3. Y una evolución claramente diferenciada hasta el extremo que la Diputación provincial, a diferencia del consejo departamental, llegará a constituir el punto clave sobre el que se articulará el régimen local.

Por supuesto hay también motivaciones comunes y entre ellas, bien a las claras, una preocupación por una nueva división territorial más racional que permita hacer llegar el poder al último rincón del territorio y, no menos importante, la definitiva supresión de los fueros personales y territoriales en favor de un uniformismo igualitario, así como la abolición de los señoríos jurisdiccionales.

En definitiva, el proceso de división provincial llevado a cabo en el primer tercio del siglo XIX fue el resultado de diferentes factores entre los que destacan:

1. El triunfo de los principios racionalistas ilustrados

2. El desorden y desigualdad existente en la antigua división, particularmente en Castilla

3. La difusión y expansión del modelo departamental francés

4. La abolición de las jurisdicciones señoriales por parte de las Cortes de Cádiz que socava los cimientos de organización territorial del Antiguo Régimen

5. La voluntad de visualizar en el mapa provincial la existencia y realización de un cambio político

6. La lógica de adecuar y modernizar una división administrativa a nuevas realidades urbanas

\section{LA POSTERIOR EVOLUCIÓN DEL RÉGIMEN PROVINCIAL HASTA EL FRANQUISMO}

La organización provincial que nace a partir de 1833 irá desarrollándose en un contexto complicado, el de una guerra, y evolucionando hasta adquirir unas características propias que la diferencian aún más de su pretendido equivalente francés. Entre las disposiciones posteriores al Decreto de 1833 debe destacarse el de 21 de septiembre de 1835 que establece el modo de constituir y formar las Diputaciones a cuyo frente estará la figura del ya entonces llamado Gobernador civil junto con otros representantes estatales y de un Vocal por cada uno de los partidos judiciales en que estuviese dividida la provincia. Es de señalar que en los diferentes textos que irán sucediéndose se utilizan alternativamente la denominaciones de Gobernador civil y Jefe político. Así en la Ley de 8 de enero de 1845, de organización y atribuciones de las Diputaciones Provinciales, reaparece la figura del Jefe político.

Es significativo señalar que la trama provincial de 1845 descansa en tres elementos: el Jefe político, la Diputación provincial y el Consejo provincial, figura de clara inspiración francesa y que tenía un carácter de órgano consultivo y tribunal administrativo y no sólo en materia de régimen local. Es entonces cuando empieza a vislumbrarse el doble papel de la Diputación como 
instrumento de la acción estatal en la provincia y de control de los Ayuntamientos, y a la vez se perfila una incipiente consolidación como ente local.

En cualquier caso, la idea principal será la de supervisar a los Ayuntamientos, tal como puede verse en el texto que en esta materia iba a tener mayor vigencia. Se trata de la Ley provincial de 1882 que estaría en vigor hasta el Estatuto provincial de 1925. Ley que en su artículo primero nos da una significativa definición de ella misma al declarar que «el territorio de la Nación española en la Península e Islas adyacentes, se divide para su administración y régimen en provincias». De igual modo, y como señalara Santamaría de Paredes en su Curso de Derecho Administrativo «la Diputación provincial es un cuerpo de representación popular, al cual corresponde exclusivamente la administración de los intereses particulares de la Provincia, y ejercer funciones del superior jerárquico de los Ayuntamientos». Poco más puede extraerse, a fines del XIX, de la obra de este ilustre académico, a la cual no dejaría de serle aplicable la crítica que Tocqueville hacía de otro Curso, el de Macarel, al considerar que «se afirma en lo que es, sin buscar nunca lo que debería ser». Sin embargo, debe señalarse que la cuestión provincial no era en absoluto pacífica en ese momento, habiendo discusiones que iban desde una ampliación del número de provincias a una reducción (ejemplo es la voz división territorial del Diccionario de la administración pública de Alcubilla -1894-), pasando por volver al escenario previo a la reforma de Javier de Burgos. Por no hablar del regeneracionismo que realizó contundentes críticas que van desde las de Joaquín Costa en 1898 a las de Ortega tres décadas después.

La Ley provincial atribuía la administración de la provincia al gobernador, a la Diputación provincial y a la Comisión. El Gobernador era un funcionario nombrado por el Gobierno, mientras que los Diputados resultaban de la agrupación de cada dos partidos judiciales colindantes en un distrito que elegía cuatro diputados, pudiendo votar cada elector a tres candidatos. Todo ello producía como escribiría Posada «una combinación desigual de los elementos burocráticos y representativo». Sin embargo, la Ley municipal de 1877 ya había reservado a la Administración del Estado poderes fundamentales de control sobre los Ayuntamientos a través del Gobernador con sus amplias facultades de intervención. De este modo la Comisión provincial quedaba como la representación ejecutiva de la Diputación siendo sus funciones las de cuerpo administrativo, superior jerárquico de los Ayuntamientos y cuerpo consultivo del gobernador y del gobierno. Finalmente, hay que señalar que la Comisión perdía su condición de Tribunal contencioso-administrativo ya que en lo sucesivo los recursos de los Ayuntamientos contra las decisiones de la Diputación y el Gobernador serían entendidos por los tribunales, y no por las mismas autoridades que dictaron la resolución.

La Ley provincial de 1882, sancionada por Alfonso XII, perduraría durante toda la Restauración hasta la asunción del poder por el Directorio militar presidido por Miguel Primo de Rivera en septiembre de 1923. El nuevo 
ciclo político supuso una inicial militarización del aparato administrativo del Estado que llevó a la disolución de todos los Ayuntamientos el 30 de septiembre, mientras que las Diputaciones lo serían durante el mes de enero de 1924.

Dos son los frentes que el Dictador pretende entonces afrontar. De un lado el caciquismo que tenía su origen en los Ayuntamientos y terminaba en los despachos ministeriales; de otro la «cuestión regional». Y dos son las normas que, de la mano de José Calvo Sotelo, pretenden dar respuesta a esos retos. De un lado el Estatuto Municipal de 8 de marzo de 1924; de otro el Estatuto Provincial aprobado por Real Decreto-Ley de 10 de marzo de 1925.

El primero, de gran perfección técnica y garantista de la autonomía, quedó frustrado en su aplicación por diversas razones, entre ellas por el mismo intervencionismo en los municipios del gobierno y de los delegados gubernativos. Por su parte, el Estatuto provincial debe ser contextualizado en un escenario en el que la llamada cuestión catalana estaba bien presente en el debate político de la época. En este sentido la Mancomunidad de Cataluña, si bien en un primer momento fue mantenida por el Directorio militar, sufrió la tensión política del momento, alcanzando la misma tal grado que terminó con la disolución de todas las Diputación provinciales de España, salvo las tres vascas y de Navarra, si bien en estos casos la designación de los diputados provinciales sería hecha por los respectivos Gobernadores civiles. El Estatuto Provincial de 1925 supuso «el gravísimo error», en palabras del Profesor García de Enterría, del desmantelamiento de la Mancomunidad de Cataluña a través de su Disposición Transitoria quinta que disponía la liquidación de los servicios mancomunales y la reasunción de sus competencias por las Diputaciones de Tarragona, Lérida y Gerona. En todo caso, el Estatuto provincial reforzó la realidad de la provincia como ente local y mejoraba sustancialmente su financiación. Y es entonces cuando surge la quincuagésima provincia con la división de Canarias en dos provincias mediante el Real Decreto-ley de 21 de septiembre de 1927.

La caída del Directorio y la proclamación de la República supuso un nuevo escenario político no exento de convulsiones en el que el debate territorial cobraría un papel principal. Así lo ponía de relieve la propia Constitución republicana cuando en su artículo 8 decía que el Estado español, «dentro de los límites irreductibles de su territorio actual», «estará integrado por Municipios mancomunados en provincias y por las regiones que se constituyan en régimen de autonomía». Vemos, pues, la aparición de un nuevo nivel administrativo, la región, a la que, de hecho, en la legislación primoriverista ya se hacía alguna referencia. Desde luego en el debate territorial de la época el tema de la división provincial no iba a resultar prioritario. Y menos aún en Cataluña donde se iba a poder implantar una división propia -la comarcalprescindiendo de las provincias.

$\mathrm{Al}$ régimen republicano sucede el régimen franquista que en el tema provincial dejaría en sustancia las cosas tal como estaban con anterioridad a 
1931, si bien bajo una nueva ley que será la Ley de Bases de Régimen Local de 1945, objeto de ulteriores modificaciones.

\section{LA CONSTITUCIÓN ESPAÑOLA DE 1978 Y LA GARANTÍA CONSTITUCIONAL DE LA PROVINCIA}

Es así que llegamos al momento constituyente de 1978, cuando nuevamente el tema territorial se plantará como uno de los más espinosos y siendo el de la provincia uno de los más polémicos, tal como destacara el Profesor S. Martín Retortillo al señalar que durante la elaboración de la Constitución Española de 1978 (CE) llegó a cuestionarse su supervivencia, tratándose en el fondo de una cuestión de poder. Con todo, la provincia obtiene un más que significado papel, en tanto que el artículo 137 sanciona que el Estado se organiza territorialmente en municipios, provincias y Comunidades Autónomas. Gozando todas estas entidades de autonomía para la gestión de sus propios intereses.

Pero además, la provincia, a partir del artículo $141.1 \mathrm{CE}$, tiene una doble función constitucional:

- Por un lado es una división territorial para el cumplimiento de los fines del Estado:

o Circunscripción electoral (art. 68.2 para el Congreso y 69.2 para el Senado, si bien en el caso de las provincias insulares la circunscripción será la Isla.)

- Aunque no lo prevé explícitamente el texto constitucional, la provincia sirve también como órgano territorial de la Administración General del Estado (artículo 29 de la LOFAGE $-6 / 1997-)$

o Incluso, el artículo 158.2 llega a reconocerle, en su caso, como destino de las inversiones articuladas a través del Fondo de Compensación Interterritorial. Si bien dicho precepto haría referencia a aquellas provincias que en su caso no formasen parte de una Comunidad Autónoma. Así se desprende de la legislación del fondo cuando define sus ámbitos territoriales en función de las Comunidades Autónomas.

- Por otro lado, la provincia es una entidad local, dotada de autonomía para la gestión de sus intereses (art. 137 CE y definida así también en la LRBRL). Tal entidad local viene determinada por la agrupación de municipios, tiene personalidad jurídica propia y es administrada y gestionada autónomamente por una corporación representativa (art. 141.2 CE): la Diputación provincial. En las islas, la institución y administración supramunicipal se denomina cabildo (Canarias) o Consell (Baleares)

Sin embargo, pese a ese explícito reconocimiento constitucional, la provincia ha sido objeto desde entonces de un constante cuestionamiento desde 
diferentes frentes. Una cruda realidad que se refleja por ejemplo en un documento importante como fue el Libro Blanco para la Reforma del Gobierno Local de 2005 cuando reconocía que las Comunidades Autónomas han ido buscando su identidad institucional en pugna con el Estado y el mundo local, añadiendo que «como poderes recién alumbrados, lograron hacerse un hueco entre los dos poderes, encontrando en la provincia un objetivo propicio».

Era, pues, de esperar que surgiera el conflicto y era lógico que el mismo se ofreciese muy tempranamente en Cataluña. Concretamente en el intento de sustraer competencias de las Diputaciones hacia la Generalitat, dando lugar a una importante sentencia del Tribunal Constitucional, la STC 32/1981, en la que el Alto Tribunal pasaba a afirmar la existencia de una garantía institucional no tanto de la autonomía local como de la Provincia que frente a la «agresión» del legislador autonómico aparece como la institución a proteger. Una polémica incorporación de una categoría que ofrece unos contornos muy claros allí donde nace, en Alemania, y con relación a unas instituciones con unos rasgos claramente definidos que resultan discutibles en el caso del ámbito local español, máxime si atendemos a que la Provincia había sido no una institución portadora de una pretendida autonomía local, sino de la articulación de un Estado centralizado con lo que era lógica la situación de conflicto en el marco del proceso de descentralización política que inauguraba la CE de 1978. Otra cosa es que ciertamente, la provincia aparece y así se va a conformar en el texto constitucional como uno de las instituciones a preservar ante el cambio político.

La STC 32/1981 inicia en lo que se refiere a la provincia una destacada línea jurisprudencial de entre las que destacan otras como la 27/1987 (Diputaciones valencianas) o la 109/1998, referida al Plan Único de Obras y Servicios de Cataluña. Una jurisprudencia de la que se extraen diversas conclusiones:

1) La provincia es una entidad local que goza de autonomía para la gestión de sus intereses.

2) La provincia es una institución esencial para asegurar los principios constitucionales, estableciéndose un reducto indisponible para el legislador. Es la garantía institucional que hemos comentado que supone garantizar la existencia necesaria de la provincia como entidad local dotada de personalidad jurídica propia y determinada por la agrupación de municipios.

3) La garantía de la autonomía provincial en el ejercicio de sus funciones de cooperación y asistencia a los municipios, considerado como integrante del «núcleo de la autonomía provincial».

4) La garantía de una administración autónoma que tenga carácter representativo.

5) La configuración institucional de la provincia se difiere desde la Constitución al legislador ordinario que no tiene más límite que el «reducto indisponible o núcleo esencial de la institución garantizada 
por la Constitución». Un legislador que será tanto estatal como autonómico, encontrando este último otro límite en la legislación básica estatal. De ahí ese carácter bifronte del régimen jurídico de las autonomías locales (STC 84/1982, mantenido en la STC 31/2010).

El carácter bifronte del régimen local es un concepto importante por cuanto resulta consustancial al Estado autonómico ya que a diferencia de otros modelos, singularmente de corte federal, en el caso español el Estado «interioriza» la organización local hasta el extremo de hacer del municipio la organización básica del territorio nacional. En otras palabras la ordenación de la Administración local interesa al Estado, con independencia, por supuesto, que esa interiorización pueda hacerse también por parte de las CC.AA. Y esto es lo que hará el Estatuto de Autonomía de Cataluña de 2006 al crear un nuevo marco de gobierno local intermedio que es la denominada Veguería.

\section{PRESENTE Y FUTURO DE LA PROVINCIA EN EL SIGLO XXI ¿UNA NUEVA DIVISIÓN PROVINCIAL?}

En nuestra opinión, el presente de la Provincia está hoy plenamente asentado y asegurado jurídicamente. Su existencia pareciera fuera de duda pero en los últimos tiempos, especialmente durante la última campaña electoral de noviembre de 2012, la existencia, o cuando menos las funciones de las Diputaciones provinciales, han sido puestas en cuestión dentro del contexto de reducción drástica del gasto de las Administraciones públicas españolas. Luego se ha visto en ellas, según lo expuesto al inicio de este trabajo, el instrumento para racionalizar el gasto y ejercicio de funciones de ámbito local. A ello no debe ser ajeno que la Administración provincial es la menos endeuda y la que en primera instancia ha acudido en auxilio de centenares de municipios que se hallaban a un paso de la quiebra económica.

A nuestro juicio hay que prestar atención a algunos elementos de reflexión entorno a la Provincia. Atestiguado el carácter local de la misma y visto el destacado papel que debe tener en el ámbito de la cooperación local, debemos centrar nuestra atención en la propia división territorial provincial y las distorsiones político-administrativas que la misma genera actualmente, transcurridos ya más de 175 años desde su implantación.

Efectivamente, sin negar la existencia y permanencia de la provincia no parece muy lógico que el mapa provincial se haya mantenido inalterable durante casi dos centurias, con la única excepción de la creación de una provincia ya hace más de 80 años. Esa inalterada permanencia constituye, sin duda, una excepción en el ámbito europea. Tanto en Francia, como en Italia (este país ha estado inmerso en una profunda reforma de su régimen provincial) y no digamos en Alemania, ese segundo nivel administrativo que se corresponde con la provincia ha sido objeto de cambios.

Cambios lógicos si atendemos a los propios que sufre un territorio con el paso del tiempo tanto en población, como en infraestructuras y en actividad económica y comercial. Lo que podía ser coherente en el siglo XIX no tiene 
porque serlo en el XXI y, con seguridad no lo es. A ello añadamos que el propio mapa provincial ha sufrido tras la CE 1978 unos cambios sobrevenidos que han comportado un triple régimen provincial:

1) El de las provincias de régimen común: serían un total de 38

2) El de las Comunidades Autónomas (CC.AA) uniprovinciales por mor del artículo 9 de la Ley 12/1983 del proceso autonómico: Cinco, más el territorio foral de Navarra: Seis. Comunidades uniprovinciales donde por cierto ese carácter de la provincia como entidad local garantizada desde la Constitución no habría sido óbice para su desaparición lisa y llanamente.

3) El de las tres provincias forales vascas: 3 (excepción histórica, tal como se ha comentado)

4) El de las tres provincias insulares: una de ellas uniprovincial y organizadas según cabildos o consejos insulares en un número de 11 entes (141.4 CE), con la peculiar sobrerrepresentación que la CE les asegura en el Senado.

Por otro lado el papel activo que la Constitución otorga a las Provincias en los procesos de iniciativa autonómica ya ha perdido su sentido una vez asentado el mapa territorial autonómico.

Por ello, pasados treinta años de vigencia constitucional e implantación del modelo autonómico habría llegado quizás el momento de reflexionar sobre el mismo y analizar su adecuación en términos de coste beneficio y coherencia política. Coherencia en que si se admite la existencia de comunidades autónomas uniprovinciales que apenas llegan a los 400.000 habitantes, mal se entiende que no sea posible que las provincias de cinco millones y medio puedan dar origen a una nueva provincia cuando haya razones para ello. Razones que van más allá del elemento demográfico como son las geográficas, económicas y de movilidad. Y todo ello desde el más absoluto respeto al texto constitucional que ciertamente garantiza la existencia de un ente intermedio en las comunidades pluriprovinciales.

A nuestro parecer la modificación de los límites provinciales es perfectamente posible sin alterar los términos de la Constitución. Primero porque esa alteración la permite la Constitución mediante ley orgánica 141.1. Segundo porque la Constitución no establece que el número de provincias sea el de cincuenta. No hay ningún número, sólo que deben existir. Que hayan de ser cincuenta es una previsión que se contiene únicamente en el artículo 25 del Texto Refundido de Régimen local (RDLeg. 781/1986), donde se señala que el territorio de la Nación española se divide en cincuenta provincias.

La adecuación de una nueva división provincial del territorio permitiría no sólo adecuarlo a la realidad existente, sino que ofrecería la ventaja de, por ejemplo, enmarcar la división territorial de Cataluña -aspecto de controversia política permanente- en un debate supra-autonómico en el que otras CC.AA posiblemente estarían más que dispuestas a participar. El resultado no dejaría de suponer un aumento del número de provincias -no necesaria- 
mente muy superior al actual- que, lejos de suponer una hipertrofia, supondría una mejor adecuación de esta división a la realidad del territorio y junto con las medidas legislativas oportunas permitiría ejercer eficazmente el papel de ente intermunicipal y de cooperación.

Y cabe insistir en que, caso de encontrarnos ante un escenario expansivo, hablar de 75 o incluso 100 provincias no sería ningún dislate, tal como apunta el geógrafo Jesús Burgueño. Ya que es un número perfectamente homologable a los estándares europeos, tal como muestra la Nomenclatura de las Unidades Territoriales Estadísticas utilizadas por la oficina Eurostat de la Unión Europea, donde en el NUTS-3 en que se ubican las 50 provincias, encontramos los 439 Kreise alemanes, los 96 departamentos franceses o las 110 provincias italianas, por no hablar de los 93 distritos que existen únicamente en Inglaterra, dejando al margen Gales, Escocia e Irlanda del Norte.

Ello lógicamente debería incidir también sobre el régimen de representación de los órganos provinciales cuyo sistema electoral deben conocer al dedillo los partidos políticos pero que es completamente ignotos para la ciudadanía que no sólo desconoce la importancia de los partidos judiciales en este tema, sino que ni tan siquiera sabe de la incidencia del voto municipal en la elección de los diputados provinciales.

Y, por supuesto, el gran otro gran tema que debería tratarse, aunque no necesariamente, sería el del mantenimiento o no de la provincia como circunscripción electoral que, es verdad, obliga a una reforma constitucional pero la misma parece mucho menos problemática a la vista de la acelerada reforma que introdujo una extensa nueva redacción al artículo $135 \mathrm{CE}$ y, por supuesto, por no requerirlo, sin necesidad de referéndum.

Cabe reconocer, sin embargo, que el único lugar donde se ha planteado con insistencia el cambio del mapa provincial ha sido en Cataluña, sin que haya ido más allá de los ambientes políticos y los especialmente sensibilizados en la cuestión.

\section{BIBLIOGRAFÍA}

Burgueño, J., Geografía política de la España constitucional. La división provincial, Madrid, Centro de Estudios Constitucionales, 1996.

- La invención de las provincias, Madrid, Catarata, 2011.

Carballeira Rivera, M. T., La provincia en el sistema autonómico español, Madrid, Marcial Pons, 1993. Cebreiro NúÑEz, J. I., Los orígenes de la división provincial en España, Madrid, INAP, 2012.

Díaz Revorio, F. J. / Belda Pérez Pedrero, E., «La provincia y la diputación. Antecedentes, configuración constitucional y algunos argumentos a favor y en contra de su permanencia», REALA, núm. 284, 2000, pp. 649879.

Esteve Pardo, J., Organización supramunicipal y sistema de articulación entre Administración autonómica y orden local (La experiencia de la RFA. Bases y perspectivas en España), Madrid, Civitas, 1991. 
- «La experiencia provincial en Cataluña», en La provincia en el Estado de las autonomías, Madrid, Marcial Pons, 1996, pp. 11-39.

- «Garantía institucional y/o función constitucional en las bases del régimen local», $R E D C$, núm. 31, 1991. GarCía De ENTERRÍA, E., Manuel Azaña. Sobre la autonomía política de Cataluña (Selección de textos y estudio preliminar), Madrid, Tecnos, 2005.

Morán OrTí, M., «La división territorial de España: 1825-1833», REALA, núm. 247, 1990, pp. 567-599.

Morell Ocaña, L., «La concepción constitucional de la provincia como entidad local», en Estudios sobre la Constitución española. Homenaje al Profesor E. García de Enterría, Madrid, Civitas, vol. IV, 1991, pp. 3267-3299.

Orduña Rebollo, E. / Cosculluela Montaner, L., Historia de la Legislación de Régimen Local, Madrid, Iustel, 2008.

Martín-Retortillo, S., La provincia. Pasado, presente y futuro, Madrid, Civitas, 1991.

Sánchez Blanco, A., Organización intermunicipal, Madrid, Iustel, 2006.

Santamaría Pastor, J. A., Sobre la génesis del Derecho Administrativo Español en el siglo XIX (1812-1845), Iustel, 2006.

VV.AA., La provincia en el sistema constitucional (R. Gómez-Ferrer Morant, dir.), Madrid, Civitas, 1991.

RESUMEN: Este artículo ofrece una panorámica sobre los orígenes y evolución del hecho provincial en nuestro país con una apuesta por un nuevo mapa acorde con la realidad política, económica y social de la España del siglo XXI, a la luz del reciente informe de la Comisión para la Reforma de las Administraciones Públicas (CORA) y las subsiguientes medidas legislativas adoptadas (o en curso) para su implementación.

PALABRAS CLAVE: Derecho constitucional, reforma de las administraciones, medidas de austeridad, provincia.

TITLE: Spanish provincial division: History, Evolution and Current status.

ABSTRACT: This article provides an overview of the origins and evolution of the province as a territorial division mechanism in our country arguing for a new map according to the political, economic and social development of the XXI century Spain, in light of the recent report of the CORA and the subsequent legislation passed to implement it.

KEYWORDS: Constitutional law, public sector reform, austerity measures, province.

Recibido: 02.08.2013

Aceptado: 02.09.2013 